\title{
El medio en doble fase y su aplicación en el cultivo in vitro de plantas amenazadas
}

\section{F. Serrano-Martinez, M. Cano-Castillo y A. Marco-Medina}

Centro Iberoamericano de la Biodiversidad (Cibio). Universidad de Alicante, España. F.SERRANO@UA.ES

\section{ABSTRACT}

From several decades, in vitro culture techniques are being used as a suitable method for germplasm conservation. The development of micropropagation protocols for rare, endangered, threatened or endemic plant species is sometimes difficult due to the lack of previous in vitro studies. Besides the establishment of in vitro culture of this kind of species, to obtain good multiplication and rooting rates and true-to-type acclimatized plants are main objectives to be achieved with the micropropagation protocols. Problems with the choice of the type and/ or concentration of growth regulators are common in this kind of studies, resulting in callus formation and/or hyperhydricity. According to our experience, the double-phase culture system is a method that can improve growth and/or multiplication rate of in vitro-cultured plants. Since the preparation of the double-phase culture media is easy and the evaluation of the results obtained is fast, experiments to test its effects in the growth and development of in vitro-cultured plants could be of interest to achieve the aim of conservation.

\section{KEY WORDS:}

Double phase, in vitro culture, conservation, micropropagation

\section{INTRODUCCIÓN}

Desde la publicación en 1902 del que es considerado el primer trabajo sobre cultivo in vitro de plantas (HABERLANDT, 1902), el desarrollo experimentado en este campo ha constituido una de las piedras angulares para el desarrollo de lo que hoy en día conocemos con el nombre de "Biotecnología Vegetal" (VASIL, 2008). Sin duda, esta tecnología es fuente de innumerables beneficios para la sociedad, tales como la producción de metabolitos secundarios, nuevas técnicas de mejora vegetal, obtención de plantas libres de virus, y un largo etcétera en el que también encontramos la aplicación de las técnicas de cultivo in vitro a la conservación ex situ de especies vegetales. Desde hace décadas, estas técnicas se vienen empleando específicamente para la conservación de especies raras, endémicas, amenazadas, o 
en peligro de extinción (ver SARASAN et al. 2006). Sin embargo, a pesar del cada vez mayor desarrollo de esta tecnología y que el número de especies conservadas (y amenazadas) continua aumentando, cabe comentar que cultivar y propagar in vitro este tipo de especies sigue planteando dificultades en parte debido a: 1) normalmente no existen trabajos sobre cultivo in vitro realizados con muchas de las especies a conservar que puedan servir de referencia, 2) el material de partida suele ser en ocasiones escaso y 3) al igual que con otras especies, son muchas las variables que hay que tener en cuenta para poder realizar protocolos de propagación exitosos, entre las que se encuentran principalmente las características del medio de cultivo (concentración y tipo de sales, agar, fuente de carbono...) y el tipo y concentración de reguladores del crecimiento, entre otras.

Una de las líneas de investigación que se ha llevado a cabo en el CIBIO durante los últimos años ha sido precisamente el desarrollo de estrategias de conservación mediante técnicas de cultivo in vitro para especies con algún grado de amenaza o interés que están presentes en las provincias de Alicante y Murcia (sureste de España), zona con una gran diversidad vegetal. Durante el desarrollo de los protocolos de micropropagación, además de realizar los pasos "tradicionales" o "clásicos" para determinar y optimizar los mismos (evaluar diferentes protocolos de esterilización, combinaciones de vitaminas, macro- $y$ microelementos, y otros elementos en el medio de cultivo, concentraciones y tipos de citoquininas y auxinas para multiplicar y/o enraizar, etc.), hemos realizado ensayos para evaluar la eficacia del medio en doble fase para la mejora del crecimiento in vitro de los explantos.

\section{EL CULTIVO IN VITRO EN DOBLE FASE}

Los medios (o sistemas) en doble fase se caracterizan por la disposición de una capa estática de medio líquido por encima de un medio semisólido (GEORGE \& DAVIES, 2008). Los objetivos para los que se ha aplicado tal sistema son muy variados. Algunos de ellos son: la búsqueda de un método para incrementar la elongación y calidad de los explantos (SERRANO-MARTINEZ, 2009); la optimización del cultivo in vitro (KOMOZARA et al., 2008); la solución de desórdenes fisiológicos como la hiperhidratación (PIQUERAS et al., 1998); o la minimización del coste y la manipulación para elongar y enraizar explantos en la micropropagación de especies de interés comercial (MAENE \& DEBERGH, 1985). Obviamente, la composición de estos medios, condiciones y tiempo de aplicación variarán dependiendo de las necesidades de cada especie. Algunos ejemplos donde se ha aplicado el cultivo en doble fase se presenta en la tabla 1 .

Lógicamente, no siempre se obtienen buenos resultados empleando sistemas en doble fase. Por ejemplo, en Persea americana (ver tabla 1), se produjo un mayor porcentaje explantos hiperhidratados, además de cambios morfológicos asociados a la aplicación de este sistema y su respuesta fisiológica. De hecho, no cabe duda que la presencia de la fase líquida tiene consecuencias metabólicas y fisiológicas en los explantos (DE LA VIÑA et al., 2001; PIQUERAS et al., 1998), y es lógico pensar que éstas dependerán no solo del sistema de cultivo sino también de la composición de la fase líquida que dispongamos e incluso de la especie sobre la que se aplique, entre otras variables. Sin embargo, diferentes autores coinciden en señalar que la adición de medio líquido implicaría una mejor disponibilidad de nutrientes (y reguladores de crecimiento si los hubiere) en comparación con el medio semisólido en solitario. Esto es en parte debido a que con el medio líquido aumenta la superficie de absorción de los nutrientes y existe una mayor difusión de las moléculas además de mejorarse la capacidad de eliminar y diluir los productos de desecho derivados del explanto.

Teniendo en cuenta todos estos antecedentes, es factible pensar que evaluar este tipo de sistemas de cultivo podría ser una buena alternativa para mejorar el crecimiento y la calidad de las plántulas in vitro sobre las que estemos desarrollando protocolos de micropropagación. 


\begin{tabular}{|c|c|c|c|c|}
\hline Especie & Medio sólido & Medio líquido & Resultado & Referencia \\
\hline $\begin{array}{l}\text { Pyrus } \\
\text { pyrifolia }\end{array}$ & $\begin{array}{c}\text { WPM } \\
20 \mathrm{gl}^{-1} \text { sorbitol } \\
0.1 \mathrm{mgl}^{-1} \mathrm{AIB} \\
2.5 \mathrm{mgl}^{-1} \mathrm{BAP} \\
8 \mathrm{gl}^{-1} \text { agar }\end{array}$ & $\begin{array}{l}\text { Misma composición que } \\
\text { el sólido pero sin agar }\end{array}$ & $\begin{array}{c}\text { Aumento de peso fresco y } \\
\text { velocidad de proliferación de } \\
\text { tallos }\end{array}$ & $\begin{array}{l}\text { KADOTA et al. } \\
2001\end{array}$ \\
\hline $\begin{array}{l}\text { Chynomanthus } \\
\text { praecox }\end{array}$ & $\begin{array}{c}\text { Sales MS } \\
\text { Vitaminas LS } \\
30 \mathrm{gl}^{-1} \text { sacarosa } \\
1 \mathrm{gl}^{-1} \mathrm{AC} \\
0.5 \mathrm{mgl}^{-1} \mathrm{BAP} \\
6.4 \mathrm{gl}^{-1} \mathrm{agar}\end{array}$ & $\begin{array}{l}\text { Misma composición que } \\
\text { el sólido pero sin agar }\end{array}$ & $\begin{array}{l}\text { Mejora del crecimiento de tallos. } \\
\text { Reducción de necrosis apical }\end{array}$ & $\begin{array}{l}\text { KOMOZARA et al. } \\
\qquad(2008)\end{array}$ \\
\hline Pinus taeda & (1) & (1) & $\begin{array}{l}\text { Estimulación de la iniciación de } \\
\text { tejido embriogénico }\end{array}$ & $\begin{array}{c}\text { PULLMAN \& } \\
\text { SKRYABINA (2007) }\end{array}$ \\
\hline $\begin{array}{l}\text { Nicotiana } \\
\text { tabacum (2) }\end{array}$ & $\begin{array}{c}\text { MS } \\
20 \mathrm{gl}^{-1} \text { sacarosa } \\
1 \mathrm{mgl}^{-1} \mathrm{BAP} \\
4 \mathrm{gl}^{-1} \mathrm{BDH} \text { agar } \\
3 \mathrm{gl}^{-1} \text { Roth agar }\end{array}$ & $\begin{array}{l}1 / 2 \text { sales Knop } \\
50 \mathrm{gl}^{-1} \text { sacarosa } \\
3 \mathrm{gl}^{-1} \mathrm{CA}\end{array}$ & $\begin{array}{c}\text { Reducción del porcentaje de } \\
\text { hiperhidratación. }\end{array}$ & $\begin{array}{l}\text { PIQUERAS et al. } \\
\text { (1998) }\end{array}$ \\
\hline $\begin{array}{l}\text { Persea } \\
\text { americana }\end{array}$ & $\begin{array}{c}\text { MS (1/2 macroelementos) } \\
2.89 \mu \text { M BAP } \\
1.7 \mathrm{gl}^{-1} \text { gelrite }\end{array}$ & $\begin{array}{c}\text { MS }(1 / 2 \\
\text { macroelementos }) \\
0.44 \mu \mathrm{M} \text { BAP }\end{array}$ & $\begin{array}{l}\text { Aumento de la hiperhidratación. } \\
\text { Menor área foliar. Aumento de } \\
\text { longitud del tallo principal }\end{array}$ & $\begin{array}{l}\text { DE LA VIÑA et al. } \\
\text { (2001) }\end{array}$ \\
\hline
\end{tabular}

Tabla 1: Algunos ejemplos de especies donde se han empleado medios en doble fase.

Abreviaturas: AIB (ácido indolbutírico); BAP (benzilaminopurina); CA (carbón activo); LS (medio Linsmaier y Skoog); MS (medio Murashige y Skoog); WPM (woody plant medium)

(1) Debido a la complejidad de los medios de cultivo, no se describen en el cuadro. Emplazamos al lector a la referencia descrita

(2) Aplicación conjunta de medio en doble fase y enfriamiento basal ("bottom cooling")

\section{APLICACIÓN DE LOS MEDIOS EN DOBLE FASE A LA CONSERVACIÓN IN VITRO DE PLANTAS AMENAZADAS}

Hemos estudiado la respuesta a los medios en doble fase de diferentes especies de plantas amenazadas cultivadas in vitro (tabla 2). Para ello, sobre el medio semisólido adecuado para cada una de ellas, dispusimos una fase líquida, basada en variaciones de la descrita por PIQUERAS et al. (1998) y que consta de solución de Knop (tabla 3) a la mitad de su concentración (1/2 Knop), 50 gl-1 de sacarosa y 30 gl-1 de carbón activo (CA), todo ello ajustado a pH 5.0 antes del autoclavado.

Nuestro objetivo inicial era encontrar un método que nos permitiese aumentar la elongación de especies que presentaban un crecimiento lento en condiciones in vitro, como eran Tetraclinis articulata y Sorbus aria. Para ello, se ańadieron 2-3 ml (en tubos de cultivo de $2.5 \times 15 \mathrm{~cm}$; rellenando de nuevo cuando fuese necesario) de la fase descrita en el párrafo anterior variando además la concentración de CA. Este mismo ensayo fue también realizado en Thymus moroderi (MARCO-MEDINA, 2010). Observamos que su aplicación mejoraba significativamente el crecimiento de los explantos (figura 1), demostrando su aplicabilidad a especies muy diferentes. Además, la concentración de CA en la fase líquida parecía tener un papel importante en la eficacia del sistema, especialmente en $T$. moroderi. 


\begin{tabular}{|c|c|c|c|c|}
\hline Especie & Medio sólido & Medio líquido & Categoría & Resultado \\
\hline $\begin{array}{c}\text { Astragalus } \\
\text { nitidiflorus } \\
\text { (Leguminosae) }\end{array}$ & $\begin{array}{c}\text { MS } \\
30 \mathrm{gl}^{-1} \text { sacarosa } \\
0.01 \mathrm{gl}^{-1} \mathrm{Fe} \text {-sequestrene } \\
6 \mathrm{gl}^{-1} \text { Plant agar }\end{array}$ & $\begin{array}{l}1 / 2 \text { sales Knop } \\
50 \mathrm{gl}^{-1} \text { sacarosa } \\
3 \mathrm{gl}^{-1} \mathrm{CA}\end{array}$ & $\begin{array}{c}\text { "En peligro crítico" (CR) } \\
(1)\end{array}$ & $\begin{array}{l}\text { Aumento de la elongación y } \\
\text { porcentaje de enraizamiento }\end{array}$ \\
\hline $\begin{array}{l}\text { Helianthemum } \\
\text { marminorense } \\
\text { (Cistaceae) }\end{array}$ & $\begin{array}{c}\text { WPM } \\
20 \mathrm{gl}^{-1} \text { sacarosa } \\
6 \mathrm{gl}^{-1} \text { Plant agar }\end{array}$ & $\begin{array}{l}1 / 2 \text { sales Knop } \\
3 \mathrm{gl}^{-1} \mathrm{CA}\end{array}$ & $\begin{array}{l}\text { "En peligro" (EN) (1). } \\
\text { "Vulnerable" (VU) (2) }\end{array}$ & $\begin{array}{l}\text { Aumento de la elongación y } \\
\text { el número de nudos }\end{array}$ \\
\hline $\begin{array}{l}\text { Sorbus aria } \\
\text { (Rosaceae) }\end{array}$ & $\begin{array}{c}\text { MS } \\
30 \mathrm{gl}^{-1} \text { sacarosa } \\
6 \mathrm{gl}^{-1} \text { Plant agar } \\
10 \mathrm{mg} \mathrm{l}^{-1} \text { sequestrene }\end{array}$ & $\begin{array}{c}1 / 2 \text { sales Knop } \\
50 \mathrm{gl}^{-1} \text { sacarosa } \\
6 \mathrm{gl}^{-1} \mathrm{CA}\end{array}$ & “En peligro” (2) & Aumento de la elongación \\
\hline $\begin{array}{c}\text { Tetraclinis } \\
\text { articulata } \\
\text { (Cupressaceae) }\end{array}$ & $\begin{array}{c}\mathrm{SH} \\
30 \mathrm{gl}^{-1} \text { sacarosa } \\
6.5 \mathrm{gl}^{-1} \text { Plant agar }\end{array}$ & $\begin{array}{c}1 / 2 \text { sales Knop } \\
10 \mathrm{gl}^{-1} \text { sacarosa } \\
3 \mathrm{gl}^{-1} \mathrm{CA}\end{array}$ & "Vulnerable" (VU) (1) (2) & Aumento de la elongación \\
\hline $\begin{array}{l}\text { Thymus moroderi } \\
\text { (Labiatae) }\end{array}$ & $\begin{array}{c}\text { MS } \\
30 \mathrm{gl}^{-1} \text { sacarosa } \\
7 \mathrm{gl}^{-1} \text { Plant agar }\end{array}$ & $\begin{array}{c}1 / 2 \text { sales Knop } \\
30 \mathrm{gl}^{-1} \text { sacarosa } \\
6 \mathrm{gl}^{-1} \mathrm{CA}\end{array}$ & $\begin{array}{l}\text { “Casi amenazada” (NT) } \\
(1) \\
\text { "Vulnerable" (VU) (2) }\end{array}$ & $\begin{array}{c}\text { Aumento de la elongación } \\
\text { y multiplicación. Mayor } \\
\text { desarrollo de raíces }\end{array}$ \\
\hline
\end{tabular}

Tabla 2: Algunas especies amenazadas y/o de interés sobre las que se han aplicado medios en doble fase. Abreviaturas: SH (Schenk and Hildebrandt)

(1) Lista Roja 2008 de la Flora Vascular Española (MORENO, 2008); (2) Libro Rojo de la Flora Silvestre Protegida de la Región de Murcia (SÁNCHEZ et al., 2002)

\begin{tabular}{c|c}
\hline \multicolumn{2}{|c}{ Componentes solución de Knop (gl $\left.{ }^{-1}\right)$} \\
\hline $\mathrm{KNO}_{3}$ & 0.2 \\
\hline $\mathrm{Ca}\left(\mathrm{NO}_{3}\right)_{2}$ & 0.8 \\
\hline $\mathrm{KH}_{2} \mathrm{PO}_{4}$ & 0.2 \\
\hline $\mathrm{MgSO}_{4} \cdot 7 \mathrm{H}_{2} \mathrm{O}$ & 0.2 \\
\hline
\end{tabular}

Tabla 3: Composición de la solución de Knop

Posteriormente, la composición de la fase líquida fue optimizada en T. articulata (SERRANO-MARTÍNEZ, 2009) y variaciones de la misma fueron evaluadas también con éxito en Astragalus nitidiflorus (CANO-CASTILLO et al., 2009) y Helianthemum marminorense (CANO-CASTILLO, en prep.).

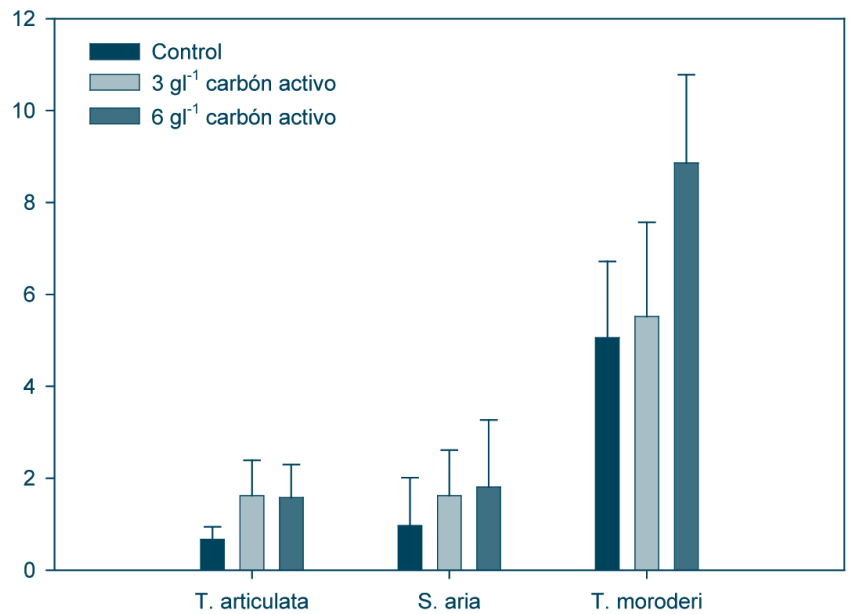

Figura 1: Evaluación de un sistema de doble fase en la elongación in vitro

En este último caso, además de mejorar la elongación, observamos que gracias a ello, los explantos produjeron un mayor número de nudos, aumentando así la capacidad de multiplicación. Durante los ensayos de multiplicación en $H$. marminorense, la aplicación de reguladores de crecimiento producía 
un aumento del número de tallos pero acompañado de un incremento del porcentaje de hiperhidratación y formación de callo basal, dando lugar a tallos adventicios en esta zona. Cuando nuestro objetivo es la conservación de germoplasma, la aparición de callo y las estructuras organogénicas que de él deriven, deben ser evitadas ya que existe una mayor probabilidad de variación somaclonal. En cualquier caso, esta suele ser una respuesta bastante común cuando la elección del regulador, su concentración y el tiempo de exposición al mismo no son los adecuados. Cuando esto sucede, una solución es evaluar de nuevo esas variables, con el consiguiente empleo de material vegetal y tiempo para obtener la respuesta morfogénica deseada y tener una mayor certeza de que las plantas que se obtendrán posteriormente no sean diferentes genéticamente a las originales.

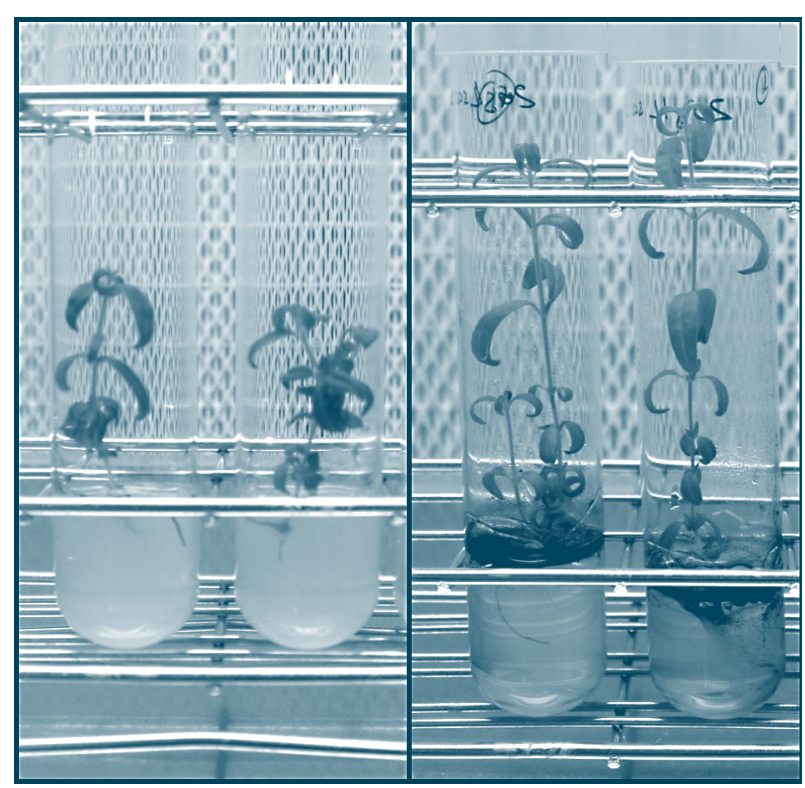

Figura 2: Diferencia de altura entre explantos de Helianthemum marminorense cultivados en medio semisólido (izqda.) y en doble fase (dcha.)

Gracias al aumento del número de nudos en $H$. marminorense y la ausencia de callo basal, la aplicación del sistema de doble fase se postuló como una alternativa para aumentar la tasa de multiplicación (aunque en menor medida que con los reguladores) disminuyendo la probabilidad de variación genética en $H$. marminorense.
Sin embargo, como regla general, hay que tener en cuenta que los resultados obtenidos corresponden a experimentos puntuales y que el cultivo prolongado en doble fase no se ha evaluado en todas estas especies. Éste podría dar lugar a hiperhidratación debido a la presencia de medio líquido, tal y como observamos en estudios posteriores en T. articulata. En el caso de T. articulata donde también se observó un engrosamiento de la base del explanto con posible aparición de callo si la doble fase se mantenía durante 6-8 semanas seguidas (SERRANO-MARTÍNEZ, 2009). Por este motivo, el tiempo de exposición debe también ser tenido en cuenta, así como quizás, la posibilidad de alternar su uso con el cultivo en medio semisólido.

\section{CONCLUSIÓN}

El cultivo en medios en doble fase ha sido empleado con éxito para mejorar la capacidad morfogénica, el crecimiento y calidad de los explantos establecidos in vitro, tanto en especies de interés comercial como en especies amenazadas. Ante esto, y teniendo en cuenta que su preparación es fácil y la evaluación de los resultados es rápida, el planteamiento de su evaluación como parte del protocolo de micropropagación o bien para la solución de problemas acontecidos durante el desarrollo del mismo (bajas tasa de crecimiento o enraizamiento, problemas con la aplicación de reguladores,...) debería tenerse en cuenta. Al igual que ocurre con otras variables, la adecuada composición de la fase líquida para cada especie necesita ser optimizada en cada caso. Para ello, el conocimiento previo del investigador sobre el comportamiento in vitro de la especie sobre la que trabaja es crucial, al igual que la existencia de referencias previas, lo que es complicado en el caso de las especies amenazadas. Sin embargo, los buenos resultados obtenidos en nuestro laboratorio con diferentes especies empleando variaciones de una misma fase líquida (modificando las concentraciones de sus componentes, especialmente la sacarosa, o eliminando algunos de ellos) pueden tomarse como punto de referencia para realizar los ensayos preliminares. 


\section{REFERENCIAS}

CANO-CASTILLO, M., SERRANO-MARTÍNEZ, F. \& CASAS, J. L. 2009. In vitro propagation of Astragalus nitidiflorus (Leguminosae), an endemic and endangered species from south-east of Spain. Acta Hort. 812:545-550.

DE LA VIÑA, G., BARCELÓ-MUÑOZ, A. \& PLIEGOALFARO, F. 2001. Effect of culture media and irradiance level on growth and morphology of Persea americana Mill microcuttings. Plant Cell Tiss. Organ Cult. 65:229-237.

GEORGE, E. F. \& DAVIES, W. 2008. Effects of the Physical Environment. En: George, E. F., Hall, M. A., De Klerk, G. J. (eds.), Plant propagation by tissue culture. Vol 1 The Background. 3rd edition, Springer. Pp 423-465

HABERLANDT, G. 1902. Kulturversuche mit isolierten Pflanzenzellen. Sitzungsber K Preuss Akad Wiss Wien. Math Naturwiss. 111:69-92.

KADOTA, M., IMIZU, K. \& HIRANO, T. 2001. Double phase in vitro culture using sorbitol increases shoot proliferation and reduces hyperhydricity in Japanese pear. Scientia Hort. 89:207-215.

MAENE, L. \& DEBERGH, P. 1985. Liquid medium additions to established tissue cultures to improve elongation and rooting in vivo. Plant Cell Tissue Organ Cult. 5:23-33.

MARCO-MEDINA, A. 2010. Aplicación de técnicas de cultivo in vitro a la conservación de Thymus moroderi Pau ex Martínez. Tesis Doctoral. Universidad de Alicante
MORENO, J. C. (coord.). 2008. Lista Roja 2008 de la flora vascular española. Dirección General de Medio Natural y Política Forestal (Ministerio de Medio Ambiente, y Medio Rural y Marino, y Sociedad Española de Biología de la Conservación de Plantas), Madrid, 86 pp.

PIQUERAS, A., HAN, B. H., VAN HUYLENBROECK, J. M. \& DEBERGH, P. C. 1998. Effect of different environmental conditions in vitro on sucrose metabolism and antioxidant enzymatic activities in cultured shorts of Nicotiana tabacum L. Plant Growth Regul. 25:5-10.

PULLMAN, G. \& SKRYABINA, A. 2007. Liquid medium and liquid overlays improve embryogenic tissue initiation in conifers. Plant Cell Rep. 26:873-887.

SÁNCHEZ, P., CARRIÓN, M. A., HERNANDEZ, A. \& GUERRA, J. 2002. Libro Rojo de la Flora Silvestre Protegida de la Región de Murcia. DGMN. Región de Murcia

SARASAN, V., CRIPPS, R., RAMSAY, M., THERTON, C., McMICHEN, M., PRENDERGAST, G. \& ROWNTREE, J. 2006. Conservation in vitro of threatened plants - progress in te past decade. In Vitro Cell. Dev. Biol Plant. 46:206-214.

SERRANO-MARTINEZ, F. 2009. Propagación y conservación de Tetraclinis articulata (Vahl) Masters mediante técnicas de cultivo in vitro. Tesis Doctoral. Universidad de Alicante.

VASIL, I. K. 2008. A history of plant biotecnology. Plant Cell Rep. 27: 1423-1440. 